\title{
Factors associated with mortality in neonatal surgical emergencies in a developing tertiary hospital in Nigeria
}

\author{
Iniabasi U. Ilori ${ }^{{ }^{*}}$, Akpabio M. Ituen ${ }^{2}$, Catherine S. Eyo ${ }^{1}$ \\ ${ }^{1}$ Department of Anaesthesia, University of Uyo Teaching Hospital, Uyo, Nigeria \\ ${ }^{2}$ Department of Surgery, University of Uyo Teaching Hospital, Uyo, Nigeria \\ Email: *iniabasi25@yahoo.com
}

Received 2 July 2013; revised 1 August 2013; accepted 9 August 2013

Copyright (c) 2013 Iniabasi U. Ilori et al. This is an open access article distributed under the Creative Commons Attribution License, which permits unrestricted use, distribution, and reproduction in any medium, provided the original work is properly cited.

\begin{abstract}
Background: The outcome of neonatal surgery depends on safe anaesthesia, competent surgery and good nursing care. The University of Uyo Teaching Hospital, Uyo, Nigeria, established in February 2008, has specialist anaesthetic and surgical manpower. The aim of the study was to determine the outcome and contributing factors to mortality in neonatal surgical emergencies at this new tertiary health institution. Method: It was a retrospective descriptive study of neonates that underwent emergency surgery at the University of Uyo Teaching Hospital between June 2008 and May 2011. Data was obtained from the anaesthetic register, ward admission and discharged register, nurses report books and patient case files. Results: Forty-five neonates were operated upon during the three year period. There were 28 males and 17 females with a male to female ratio of 1.7:1. Forty-four $(97.8 \%)$ of the neonates were referred to the University of Uyo Teaching Hospital. The mean age and body weight at presentation were $47.5 \pm 44.4$ hours and $2.65 \pm 0.61 \mathrm{~kg}$ respectively. The mean interval between admission and surgical intervention was $4.9 \pm 6.2$ days. Malformations of the gut $(40 \%)$ and anterior abdominal wall (26.7\%) were the major pathologies. The overall mortality following surgery was $62.2 \%$. Case fatality rates ranged from $0 \%$ for Hirschprung's disease to $100 \%$ for tracheoesophageal fistula. The immediate causes of death among these neonates were peritonitis from gangrenous gut, hypovolaemia and repeat surgery. Contributing factors to mortality were delivery in unorthodox health facilities, delay in presentation as well as surgical intervention and inefficient postoperative monitoring. Conclusion: Emergency neonatal surgeries at the UUTH are associated with unacceptable high mortality. Reduction in such mortality would require cam-

\footnotetext{
*Corresponding author.
}

paign for early presentation, a lot more timely surgical interventions and upgrading of monitoring facilities to help in improving perioperative monitoring and care.

Keywords: Neonatal Surgeries; Emergencies; Delays; High Mortality Rate

\section{INTRODUCTION}

The outcome of neonatal surgical emergencies has steadily improved in developed countries. This has been attributed to a better understanding of neonatal physiology, improvement in specialist surgical and anaesthetic manpower, improved diagnostic facilities and neonatal intensive care [1,2]. The University of Uyo Teaching Hospital (UUTH) is a tertiary hospital in South-South Nigeria which evolved from a secondary health facility in February 2008. It has specialist anaesthetic and paediatric surgical manpower, supportive laboratory and radiological facilities but no neonatal intensive care. It has a Special Care Baby Unit for babies delivered within the hospital and Sick Babies Unit (SBU), where sick neonates referred from other places are admitted. The SBU has 18 baby cots, five phototherapy units and nine incubators. This unit has minimal facilities for monitoring of the critically ill neonate namely a clinical thermometer, a stethoscope and a neonatal non-invasive blood pressure apparatus. The study was aimed at determining the pattern and outcome of neonatal surgical emergencies as well as contributing factors to mortality. This audit is a way of assessing the quality of neonatal surgical care and would serve as baseline data for future reviews in this young and developing tertiary hospital.

\section{MATERIALS AND METHOD}

A retrospective review of all neonates who presented 
with emergency surgical pathology and had surgery at the University of Uyo Teaching Hospital between June 2008 and May 2011 was done. Data for analysis was extracted from the anaesthetic register, ward admission and discharged register; nurses report books and patient case files. The information extracted were age and weight at presentation, sex, leading diagnosis, interval between admission and surgical intervention and place of delivery. These parameters were related to the main outcome which was mortality. Microsoft 2010 Excel was used to analyse the data and paired-T test was used to compare variables for significance. A p value of 0.05 was taken as significant. The findings are presented as simple proportion and tables.

\section{RESULTS}

Forty-five neonates were operated upon during the three year period. There were 28 males and 17 females with a male to female ratio of 1.7:1. Forty-four (97.8\%) neonates, 22 each delivered in unorthodox health facilities and peripheral hospitals were referred to the University of Uyo Teaching Hospital. Only one neonate (2\%) was delivered in the tertiary health facility (UUTH). The mean age and body weight at presentation were $47.5 \pm$ 44.4 hours (range $1-216$ hours) and $2.65 \pm 0.61 \mathrm{~kg}$ (range 1.5 - $3.7 \mathrm{~kg}$ ) respectively. The mean interval between admission and surgical intervention was $4.9 \pm 6.2$ days (range 0.3 - 27 days). All the surgeries were done by paediatric surgeons and anaesthesia was administered by consultant physician anaesthetists 20 (44\%), resident doctors in anaesthesia 17 (38\%) and nurse anaesthetists 8 (18\%). Table 1 shows the different pathologies at presentation and corresponding case fatality rates. Malformations of the gut and anterior abdominal wall were the

Table 1. Leading diagnosis and mortality rate.

\begin{tabular}{|c|c|c|c|}
\hline & Diagnosis & $\begin{array}{l}\text { Total number } \\
\text { of patients (\%) }\end{array}$ & $\begin{array}{c}\text { Case } \\
\text { fatalities (\%) }\end{array}$ \\
\hline & Intestinal obstruction & $18(40 \%)$ & $10(55.6)$ \\
\hline & Intestinal atresia & 6 & $5(83.3)$ \\
\hline \multirow[t]{4}{*}{ A } & Mid-gut malrotation & 7 & 3 (42.9) \\
\hline & Obstructed hernia & 3 & $2(66.7)$ \\
\hline & Hirschsprung's disease & 2 & $0(0)$ \\
\hline & Anterior abdominal wall defect & $12(26.7)$ & 7 (58.3) \\
\hline \multirow[t]{2}{*}{ B } & Gastroschisis & 3 & $3(100)$ \\
\hline & Omphalocoele & 8 & $4(50)$ \\
\hline $\mathrm{C}$ & Imperforate anus & $8(17.8)$ & $5(62.5)$ \\
\hline $\mathrm{D}$ & Tracheoesophageal fistula & $4(8.9)$ & $4(100)$ \\
\hline $\mathrm{E}$ & Obstructive uropathy & $2(4.4)$ & $1(50)$ \\
\hline \multirow[t]{2}{*}{$\mathrm{F}$} & Ruptured sacrococcygeal tumour & $1(2.2)$ & $1(100)$ \\
\hline & Total & 45 & $28(62.2)$ \\
\hline
\end{tabular}

major pathologies. Case fatality rates ranged from 0 $83.3 \%$ for gut malformations and $50 \%$ - $100 \%$ for the anterior abdominal wall defects. Cases of trachea-oesophageal fistula and ruptured sacrococygeal tumour were uniformly fatal. The overall mortality following surgery was $62.2 \%$. Table 2 shows the immediate causes of death among these neonates. These were peritonitis from gangrenous gut, hypovolaemia from inadequate perioperative fluid therapy and repeat surgery. Hypovolaemia, hypothermia and repeat surgery contributed to $37 \%$ of the death which occurred within the first 24 hours after surgery. Table 3 shows that there were significant differences in age at presentation ( $p=0.002)$, body weight at admission ( $p=0.04$ ) and interval between admission and surgical intervention $(p=0.02$ ) between neonates that were delivered in unorthodox and orthodox health facilities. Table 4 shows that these factors (age at presentation, the body weight and interval between admission and surgical intervention did not significantly affect outcome ( $p=0.09,0.29$ and 0.37). However, the non-survivors had a longer delay before presentation (54.5 \pm 54.8 hours), lower body weight $(2.57 \pm 0.58 \mathrm{~kg})$ and shorter duration between admission and surgical intervention (4.1 \pm 4.7 days). There were four neonates with surgical pathology who left against medical advice and were not operated upon, therefore were not included in the analysis. These were one patient each with tracheoesophageal fistula; Hirschprung's disease; omphalocoele and intestinal atresia.

\section{DISCUSSION}

The outcome of neonatal surgeries in developed countries has greatly improved due to availability of skilled and specialist healthcare professionals, improvement in diagnostic facilities and perioperative care, availability of neonatal intensive care facilities among others [1]. In developing countries, though there may be specialist health care professionals especially in tertiary health facilities, neonatal emergency surgeries are often associated with high mortality rates [2]. This may be associated with what is described as a three-delay model-delay in

Table 2. Immediate causes of death.

\begin{tabular}{|c|c|c|}
\hline Causes of death & Number of deaths & $\%$ \\
\hline Peritonitis from gangrenous gut & 17 & 60.7 \\
\hline Surgical site haemorrhage ${ }^{*}$ & $2^{\dagger}$ & 7.1 \\
\hline Anastomosis leak ${ }^{*}$ & $1^{\dagger}$ & 3.6 \\
\hline Hypovolaemia & $5^{\dagger}$ & 17.9 \\
\hline Hypothermia & $2^{\dagger}$ & 7.1 \\
\hline Indeterminate & 1 & 3.6 \\
\hline
\end{tabular}

${ }^{*}$ Mortality occurred after repeat surgery; ${ }^{\dagger}$ Death occurred within 24 hours after surgery. 
Table 3. Influence of delivery facility on risk factors.

\begin{tabular}{lll}
\hline Parameters & $\begin{array}{l}\text { Delivery in unorthodox } \\
\text { facililty (range) }\end{array}$ & \multicolumn{1}{c}{$\begin{array}{l}\text { Delivery in orthodox } \\
\text { facility }^{*} \text { (range) }\end{array}$} \\
\hline Mean age at presentation (hours) & $67 \pm 55.7(10-216)$ & $28.9 \pm 14.5(1-48)$ \\
Weight at admission (kg) & $2.5 \pm 0.5(1.8-3.7)$ & $2.9 \pm 0.7(1.5-3.7)$ \\
Interval between admission and surgical intervention (days) & $6.6 \pm 8.3(1.8-27)$ & $3.2 \pm 2.3(0.3-7)$ \\
Case fatalities & $16(72.7 \%)$ & $12(52.2 \%)$ \\
Total number of patients & 22 & 23 \\
\hline
\end{tabular}

*Only one patient was delivered in UUTH.

Table 4. Effect of risk factors on mortality.

\begin{tabular}{llc}
\hline Risk factors & Survivors (range) & Non-survivors (range) \\
\hline Age at presentation (hours) & $35.8 \pm 11.3(15-48)$ & $54.5 \pm 54.8(1-216)$ \\
Body weight at admission $(\mathrm{kg})$ & $2.78 \pm 0.68(1.5-3.3)$ & $2.57 \pm 0.58(1.8-3.7)$ \\
Interval between admission and surgical intervention & $6.1 \pm 8.1(1-27)$ & $4.1 \pm 4.7(0.3-19)$ \\
Total number of patients & 17 & 28 \\
\hline
\end{tabular}

recognition of illness, delay in seeking and accessing care and delay in the provision of care once at a health facility [3]. This three year review of neonatal surgical emergencies at a tertiary health facility in Nigeria is associated with a high mortality rate of $62.2 \%$. Neonatal surgical emergencies mortality rates in other tertiary hospitals in sub-Saharan African countries ranges from 24\% in Kenya [4], 43.1\% in Cameroun [5] and 30.5\% - 39.2\% in Nigeria [2,6-8]. The mean age at presentation was $47.5 \pm 44.4$ hours (range $1-216$ hours). This delay in presentation may be due to the fact that $44(97.8 \%)$ of the neonates were delivered outside the tertiary health facility. Absence of an efficient public emergency transportation system could also be a contributing factor. Inability to recognise the urgency of the pathology especially in neonates delivered in unorthodox health facilities (UOHF) may also have contributed to the delay. This may explain the significant difference in age at presentation between neonates delivered in UOHF and orthodox health facilities $(\mathrm{OHF})(\mathrm{p}=0.002)$. No neonate delivered in OHF presented later than 48 hours (range 1 - 48 hours). Delay in presentation as a risk factor for mortality in neonatal surgical emergencies has been reported by some authors in developing countries. Tenge-Kuremu et al. [4] in Kenya reported a median age of presentation of 3 days and Mouafo Tambo et al. [5] in Yaounde, Cameroun, a mean delay at presentation of 3.7 days. Osifo et al. in Nigeria reported that $65.5 \%$ mortality in neonatal surgical emergencies was associated with delayed presentation of which $7.5 \%$ were too ill on arrival and died during resuscitation [9]. They attributed the delay to ignorance, financial constraint, lack of adequate means of transportation among others [4,5,9]. Effect of delay in presentation on mortality is evident in neonates delivered in unorthodox health facilities having a higher mortality rate of $72.7 \%$. Training of all birth attendants in recognition of neonatal surgical emergencies and having an efficient emergency transport system especially in rural areas for immediate referral has been suggested could improve on the delay in presentation and hence mortality [10]. This might be useful in Sub-Saharan African countries as a significant percentage of the babies are often delivered at home by traditional birth attendants or in rural health centres. In this study $97.8 \%$ of the patients were referred to University of Uyo Teaching Hospital. Ameh et al. [2] in Northern and Osifo et al. [6] in Southern Nigeria reported $94.8 \%$ and $87.3 \%$ neonates with surgical emergencies were delivered at home or in rural health facilities. The preference of delivery in unorthodox health facilities, rural and private maternity centres by Nigerian women has been attributed by some authors to harsh and negative attitude of health-workers to patients, poor quality and high cost of services in government health facilities coupled with financial constraints [11-13].

There was a general delay in surgical intervention with a mean interval between admission and surgical intervention being $4.9 \pm 6.2$ days. Though the delay was significantly more in neonates that were delivered in unorthodox health facility $(\mathrm{p}=0.04)$.it did significantly affect mortality $(\mathrm{p}=0.37)$. The non-survivors, however, had a shorter interval before surgical intervention $4.1 \pm 4.7$ days (range 0.3 - 19 days). The delay was multifactorial in that some neonates needed resuscitation before intervention. Others were financial constraints in carrying out investigations, purchase of drugs and resuscitation fluids. The non survivors having a shorter interval before surgical intervention could indicate that the patients may have 
been deteriorating and resuscitation may not have been adequate before surgical intervention. The delay in surgical intervention may have contributed to the mortality of the patients with intestinal obstruction as $60.7 \%$ of the mortality was associated with peritonitis from perforation of gangrenous gut. Kamal et al. in their study of neonates with intestinal atresia in Pakistan documented gut gangrene and perforation which they also attributed to delay in presentation, as contributing factor to mortality [14]. Majority of the pathologies involved the gastrointestinal system. Anorectal malformation and intestinal obstruction were the most common pathologies (Table 1). These have been reported by several authors as the commonest indications for emergency neonatal surgical interventions [2-9]. These pathologies though amendable to surgery were associated with high mortality rates ranging from $33 \%$ for anorectal malformation to $39 \%$ for intestinal obstruction. Ademuyiwa et al. in South West Nigeria reported a mortality rate of $28.6 \%$ in neonates with intestinal obstruction. Reoperation and postoperative bleeding were the contributing factors to the mortality in their study [15]. This was also the finding in this study as none of the neonates that had reoperation as a result of anastomotic leak and postoperative bleeding survived. Other contributing factors to mortality were post-operative hypothermia and hypovolaemia as evident by poor urinary output. These and repeat surgery contributed to $37 \%$ of the death that occurred within the first 24 hours after surgery. Though all the surgeries were done by paediatric surgeons and anaesthesia administered mostly by skilled anaesthetic manpower which has been shown to improve outcome, [1,2,7,16] poor post-operative monitoring and care may have contributed to the high mortality rate. The babies, postoperatively, are admitted with other non-surgical ill neonates to the sick babies unit, which is both poorly staffed and equipped. The British Association of Paediatric Surgeons and The Royal College of Surgeons of England recommended that surgical neonates should be managed within paediatric surgical unit that is linked to neonatal intensive care unit with sufficiently trained staff who understand the special needs of the surgical neonate [17]. In a developing environment where there is paucity of trained neonatal specialist, it is difficult to envisage a specialised and dedicated neonatal surgical unit. Since the neonates are admitted in neonatal unit, the staff could be trained in neonatal life support, improved supportive care regarding temperature control as well as fluid and electrolyte management $[18,19]$. This could be useful in our hospital as hypothermia and hypovolaemia contributed to $7.1 \%$ and $17.9 \%$ of the mortality respectively. The neonatal units could also be equipped with basic automated multi-parameter patient monitors with alarm system to alert a few nursing staff, that are often on duty, in order to improve post-operative monitoring. An active collaboration between the paediatrician or neonatologist and paediatric surgical unit in the management of the surgical neonate that is admitted into the neonatal, sick babies or general paediatric unit is essential for an improved outcome.

\section{CONCLUSION}

Mortality rate following neonatal surgical emergencies is unacceptably high. Delivery in unorthodox health facilities, delay in presentation and surgical intervention and inadequate facilities for postoperative care were some of the factors that contributed to the high mortality rate recorded in this study. Education of all birth attendants in recognition of emergency neonatal surgical pathology and early referral, inclusion of neonatal surgical emergencies as essential childhood public medical service and improvement in facilities and manpower resources may reduce mortality from neonatal surgical emergencies in developing environment.

\section{ACKNOWLEDGEMENT}

We are grateful to Prof. Sylvia G. Akpan of Department of Anaesthesia, University of Uyo Teaching Hospital and Prof. E. E. Ekanem of the Department of Paediatrics, University of Calabar Teaching Hospital for their constructive criticism of the manuscript.

\section{REFERENCES}

[1] Rowe, M.I. and Rowe, S.A. (2000) The last fifty years of neonatal surgical management. The American Journal of Surgery, 180, 345-352. doi:10.1016/S0002-9610(00)00545-6

[2] Ameh, E.A., Dogo, P.M. and Nmadu, P.T. (2001) Emergency neonatal surgery in developing world. Paediatric Surgery International, 17, 448-451. doi:10.1007/s003830000551

[3] Lawn, J.E., Cousens, S. and Zupan, J. (2005) 4 million neonatal deaths: When? Where? Why? Lancet, 365, 891900. doi:10.1016/S0140-6736(05)71048-5

[4] Tenge-Kuremu, R., Kituyi, P.W., Tenge, C.N. and Kerubo, J. (2006) Neonatal surgical emergencies at moi teaching and referral hospital in Eldoret-Kenya. East and Central African Journal of Surgery, 12, 36-39.

[5] Mouafo Tambo, F.F., Chiabi, A., Ngowe Ngowe, M., Ze Minkande, J., Andze, O.G. and Sosso, M. (2011) Mortality of neonatal surgical emergencies at the gynecologyobstetric and pediatric hospital of Yaounde, Cameroon. Medecine Tropicale, 71, 206-207.

[6] Osifo, D.O. and Oriaifo, I.A. (2008) Factors affecting the management and outcome of neonatal surgery in Benin City, Nigeria. European Journal of Pediatric Surgery, 18, 107-110. doi:10.1055/s-2008-1038485

[7] Faponle, A.F., Sowande, O.A. and Adejuyigbe O. (2004) 
Anaesthesia for neonatal surgical emergencies in SemiUrban Hospital in Nigeria. East African Medical Journal, 81, 568-573.

[8] Abubakar, A.M. and Ofoegbu, C.P.K. (2003) Factors affecting outcome of emergency paediatric abdominal surgery. The Nigerian Journal of Surgical Research, 5, 8591

[9] Osifo, O.D. and Ovueni, M.E. (2009) The prevalence, patterns, and causes of deaths of surgical neonates at two African referral pediatric surgical centers. Annals of $\mathrm{Pe}$ diatric Surgery, 5, 194-199.

[10] Gangopadhyay, A.N., Upadhyaya, V.D. and Sharma, S.P. (2008) Neonatal surgery: A ten-year audit from a university hospital. Indian Journal of Paediatrics, 75, 1025-1030. doi:10.1007/s12098-008-0205-4

[11] Asuquo, E.E.J., Etuk, S.J. and Duke, F. (2000) Staff attitude as barrier to the utilisation of University of Calabar Teaching Hospital for obstetric care. African Journal of Reproductive Health, 4, 69-73. doi:10.2307/3583450

[12] Osubor, K.M., Fatusi, A.O. and Chiwuzie, J.C. (2006) Maternal health-seeking behaviour and associated factors in a rural Nigerian community. Maternal and Child Health Journal, 10, 159-169. doi:10.1007/s10995-005-0037-z

[13] Udoma, E.J., Ekanem, A.D., Abasiattai, A.M. and Bassey,
E.A. (2005) Reasons for preference of delivery in spiritual church-based clinic by women in South-South Nigeria. Nigerian Journal of Clinical Practice, 11, 100-103.

[14] Kamal, A., Khan, K., Rahman, I. and Khan, A. (2010) Small gut atresia in neonates. Journal of Ayub Medical College, Abbottabad, 22, 64-66.

[15] Ademuyiwa, A.O., Sowande, O.A., Ijaduola, T.K. and Adejuyigbe, O. (2009) Determinants of mortality in neonatal intestinal obstruction in Ile Ife, Nigeria. African Journal of Paediatric Surgery, 6, 11-13. doi:10.4103/0189-6725.48568

[16] Amponsah, G. (2010) Challenges of anaesthesia in the management of the surgical neonates in Africa. African Journal of Paediatric Surgery, 7, 134-139. doi:10.4103/0189-6725.70410

[17] Surgical Services of the Newborn (1999) Report of British Association of paediatric surgeons in collaboration with the Royal College of Surgeons of England. www.baps.org.uk

[18] Ramji, S., Kler, N. and Kaur, A. (2012) Where should surgical neonates be nursed? Journal of Neonatal Surgery, 1, 24.

[19] Simiyu, D.E. (2003) Morbidity and mortality of neonates admitted in general paediatric wards at Kenyatta National Hospital. East African Medical Journal, 80, 611-616. 